\title{
Calorimetric measurements of losses in HTS cables
}

Tønnesen, Ole; Veje, Niels Erling Winsløv; Rasmussen, Carsten; Olsen, Søren Krüger; Træholt, Chresten

Published in:

IEEE Transactions on Applied Superconductivity

Link to article, DOI:

$10.1109 / 77.920129$

Publication date:

2001

Document Version

Publisher's PDF, also known as Version of record

Link back to DTU Orbit

Citation (APA):

Tønnesen, O., Veje, N. E. W., Rasmussen, C., Olsen, S. K., \& Træholt, C. (2001). Calorimetric measurements of losses in HTS cables. IEEE Transactions on Applied Superconductivity, 11(1), 1777-1780.

https://doi.org/10.1109/77.920129

\section{General rights}

Copyright and moral rights for the publications made accessible in the public portal are retained by the authors and/or other copyright owners and it is a condition of accessing publications that users recognise and abide by the legal requirements associated with these rights.

- Users may download and print one copy of any publication from the public portal for the purpose of private study or research.

- You may not further distribute the material or use it for any profit-making activity or commercial gain

- You may freely distribute the URL identifying the publication in the public portal

If you believe that this document breaches copyright please contact us providing details, and we will remove access to the work immediately and investigate your claim. 


\title{
Calorimetric Measurements of Losses in HTS Cables
}

\author{
Chresten Træholt, Søren Krüger Olsen, Carsten Rasmussen, Erling Veje, Ole Tønnesen
}

\begin{abstract}
A calorimetric test rig is used to investigate various loss components in a $10 \mathrm{~m}$ long superconducting cable model.

A calorimetric technique, based on thermocouple measurements, is used to measure the losses of the $10 \mathrm{~m}$ long superconducting cable model. The current dependent losses are also measured electrically and compared with the losses obtained with the calorimetric method. The results obtained by the two methods are consistent.

Based on an $I^{2}$ (current) fitting procedure, the loss, caused by the eddy current generated in the stainless steel cryostat housing, and the hysteresis loss generated in the conductor can be separated. From this result, it appears that the two contributions are roughly equal in size.
\end{abstract}

Index Terms-Calorimetric test rig, losses, superconducting power cable.

\section{INTRODUCTION}

$\mathrm{C}$ HARACTERIZING a high temperature superconducting cable is imperative in order to compare the performance with conventional cables. Energy dissipation is an important factor by which cables are characterized.

The losses of a superconducting cable can be divided into thermal losses, electrical losses (eddy current, hysterctic), pumping losses, dielectric losses and refrigeration losses. In conventional cables, pumping losses and refrigeration losses are only encountered when using forced cooled cables. Dielectric losses, pumping losses and refrigeration losses are not considered in this work. Dielectric losses are neglected as they are generated at room temperature (warm dielectric cable) and have no impact on the cooling circuit. Pumping losses are negligible due to the short length of the experiment and the low flow rates that are used.

The electrical losses can be determined by electrical power factor measurements [1]. However, it is not practical to measure the thermal losses by such methods.

Manuscript received September 18, 2000. The work was carried out within the program Superconductors in the Danish Energy Sector and was supported in part by the Danish Energy Agency (Energistyreisen) and the Electric Utilities of Zealand (ELKRAFT) and ELTRA, Denmark.

$\mathrm{C}$ Træholt, E. Veje and $\mathrm{O}$ Tønnesen are with the Department of Electric Power Engineering, Technical University of Denmark, Building 325, DK2800 Lyngby, Denmark. E-mails ct@eltek.dtu.dk, ev@eltek.dlu.dk, ot@eltek.dtu.dk.

S. Kritger Olsen was with the Dep. of Electric Power Eng., Danish Technical University, Lyngby, Denmark. He is now with the Electric Utilities of Zealand (ELKRAFT SYSTEM), Denmark. E-mail sro(d)elkraft.dk.

C. Rasmussen was with the Dep. of Electric Power Eng., Technical University of Denmark, Lyngby, Denmark. He is now with Statens Institut for Strålehygiejne, Denmark. E-mail carsten.rasmussen (a)sis.dk.
Measuring the losses of a superconducting cable using an electrical method presents a challenge when the cable core is placed in a stainless steel (SS) cryostat and connected in a 3 phase configuration. Even measuring cable losses in 3 phase conventional cables is not trivial and requires the use of a phase sensitive voltmeter and careful determination of the phase angle between load the current and the voltage. For a conventional cable, the phase angle measurement is less difficult because the resistive voltage is relatively large compared with the inductive voltage. In a superconducting cable, the inductive voltage is generally much larger than the resistive voltage so the measurement becomes very sensitive to spurious magnetic fields around the conductor. The magnetic field in a 3 phase configuration thus becomes an impediment to loss measurements which rely on measuring the load current and the voltage together with the phase between them. In principle, an electrical method to determine the losses in a 3 phase superconducting cable system must rely on complete inductive compensation of the voltage signal.

Alternatively, the losses can be determined by calorimetric techniques. In this case, the electrical loss and the thermal loss can be separated in a straight-forward manner, because under zero load, only thermal losses are present, whereas under electrical load conditions, the electrical loss makes an additional contribution. The draw backs of the calorimetric method are that it suffers from inherently long time constants (sometimes hours) for thermal equilibrium and rather low sensitivity [2].

Several calorimetric techniques have been demonstrated. The methods that have been documented include: nitrogen evaporation calorimetry [3], radial temperature gradient and profile calorimetry [4], and axial temperature gradient calorimetry [2], [5]. These techniques have been compared with electrical measurements [3] - [5].

In the following, a loss measurement based on the temperature difference in flowing liquid nitrogen (LN2) is reported. The calorimetric method relies on using a set of thermocouples to monitor the temperature difference between two posistions in the LN2 circuit.

\section{EXPERIMENT}

The test rig consists of a $10 \mathrm{~m}$ long flexible cryostat (DeMaCo [6]), two custom made cable terminations, and a closed circuit liquid nitrogen (LN2) cooling system (Messer Cryotherm [7]). An HTS cable core (the conductor) is placed inside the $10 \mathrm{~m}$ long SS cryostat. Temperature sensors are placed inside and outside the conductor. Fittings in the cable terminations allow current and LN2 to be fed to the cable core. 


\section{A. Cryostat}

The $10 \mathrm{~m}$ cryostat is a double walled flexible stainless steel hose with an inner bore diameter of $50 \mathrm{~mm}$ (DN50). The inner and outer walls are thermally insulated from each other by intermediate vacuum and a sandwich of 25 aluminum foils alternating with layers of glass paper. The maximum heat leak of the cryostat is specified as $2.5 \mathrm{~W} / \mathrm{m}$. The outer corrugated wall is electrically interrupted by a ceramic insulator (30 $\mathrm{cm}$ long) in order to reduce eddy current losses during ac operation of the conductor. Each end of the cryostat can be connected to a cable termination with a Johnston coupling.

At present, the cryostat is being used in a straight configuration; however, the cryostat and the superconducting cable conductor can also be tested in a bent configuration.

\section{B. Cable Termination}

Each cable termination consists of a double walled stainless steel housing (vacuum insulated) which has the form of an inverted T-piece. The cable termination serves multiple purposes. The $2 \mathrm{kA}$ HTS conductor, the current lead (copper), and the LN2 supply each enter a branch of the T-piece. Besides joining these three branches, the cable termination must also function as a high voltage $(36 \mathrm{kV})$ to ground transition. A detailed description of the termination design can be found in [8] and [9].

\section{Cooling System}

The present experimental cooling system includes a cooling station, the two custom designed cable terminations and the $10 \mathrm{~m}$ cryostat. Vacuum insulated flexible lines connect the cooling station with the cryostat/cable using Johnston couplings. The cooling station consists of an LN2 bath, heat exchanger, circulation pump, Coriolis flow meter, and pressure chamber. The cooling in the closed circuit is obtained by flowing the circulating pressurised LN2 through a boiling bath of LN2. Thus, the bath is as buffer and cooling source. This system is capable of producing temperatures of around $78-80 \mathrm{~K}$ in the closed circuit with a cooling power of up to $2000 \mathrm{~W}$. This system facilitates experiments as a function of temperature, pressure and flow rate (cooling power).

In order to lower the temperature below the boiling point of $\mathrm{LN} 2(77 \mathrm{~K}$ at $100 \mathrm{kPa},(1 \mathrm{bar}))$, a vacuum pump (250 $\mathrm{m}^{3} / \mathrm{h}$ ) is connected to the cooling station. The vapour pressure of the LN2 bath/buffer can be controlled with the pump down between $10-100 \mathrm{kPa}(100-1000$ mbar $)$, which corresponds to the temperature range $65-80 \mathrm{~K}$. At the low pressure end, the pump characteristic corresponds to a yield of about 1000 W of cooling power (@65 K).

With a load of about $500 \mathrm{~W}$, the cooling station can be operated continuously for 24 hours (with an extra buffer tank) and is capable of operating with an overpressure of up to 1 $\mathrm{MPa}$ (10 bar). The flow range is $0.05-0.3 \mathrm{~kg} / \mathrm{s}$, and the temperature range is $65-80 \mathrm{~K}$. The characteristics of the cooling system are summarized in Table I.
TABLE I

CHARACTERISTICS OF THE COOLING SYSTEM

\begin{tabular}{lll}
\hline \multicolumn{1}{c}{ Parameter } & \multicolumn{1}{c}{ Cooling station } & Including vacuum pump \\
\hline Supply temperature & $78-80 \mathrm{~K}$ & $65-80 \mathrm{~K}$ \\
Supply pressure & $1-10 \mathrm{bar}$ & $1-10 \mathrm{bar}$ \\
Flow range & $0.05-0.3 \mathrm{~kg} / \mathrm{s}$ & $0.05-0.3 \mathrm{~kg} / \mathrm{s}$ \\
Cooling power & $2000 \mathrm{~W}$ & $1000-2000 \mathrm{~W}$ \\
\hline
\end{tabular}

\section{Cable Conductor}

The superconducting core, i.e., the conductor, consists of 193 helically wound HTS tapes which give a critical current of $3.2 \mathrm{kA} \mathrm{[1]}$. The tapes are divided into 8 layers and each end is soldered to a copper joint which provides the connections to a current lead and an LN2 feed. The tapes are wound on a hollow former with an inner diameter of $30 \mathrm{~mm}$, leaving adequate space for installing sensors, etc.

In order to measure the heat transport of the LN2 in the cable, a set of E-type thermocouples is placed in the former, i.e., in the LN2 stream. The distance between the thermocouples is $7.0 \mathrm{~m}$ in order to obtain the largest possible temperature difference and yet avoid end effects. Similarly, another thermocouple is placed in the LN2 stream spanning one cable termination. Calibrated silicon diodes (type DT $471 \mathrm{SD}$ ) are mounted on the outermost HTS tapes on the outside of the conductor (middle part) and on the superconductor to normal conductor transition. Another silicon diode is placed in the LN2 stream in order to monitor the absolute temperature. The positions of the thermocouples and the diodes are shown in Fig. 1.

For calibration purposes, a constantan heater is mounted in the LN2 stream between the set of thermocouples inside the conductor. The voltage signal from the thermocouples is monitored by two nanovoltmeters (HP 34420A). The diodes are read by a Lakeshore 330 temperature controller. The data from the thermocouples and the diodes are automatically logged versus time using a HP-VEE interface, developed for the purpose. The time interval between readings is about 45 $\mathrm{s}$. The measurement station is electrically floating whereas the conductor and the cryostat are grounded.

In all experiments, the superconductor is driven by a $50 \mathrm{~Hz}$ current source capable of giving $2000 \mathrm{~A}$ rms. Two return current paths are positioned symmetrically near the superconductor so as to minimize the influence of inductance and magnetic fields on electrical loss measurements. Details of the electrical loss measurements are found in [1].

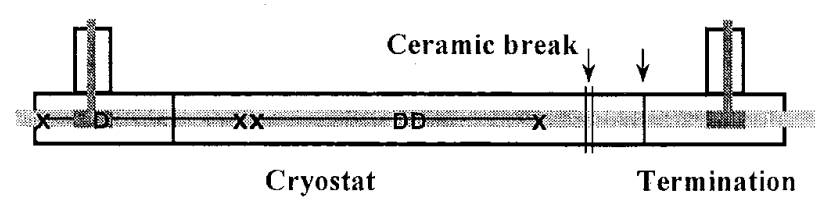

Fig. 1. Outline of the cryostat and the terminations. The X's and D's denote the positions of the thermocouples and the silicon diodes, respectively. 


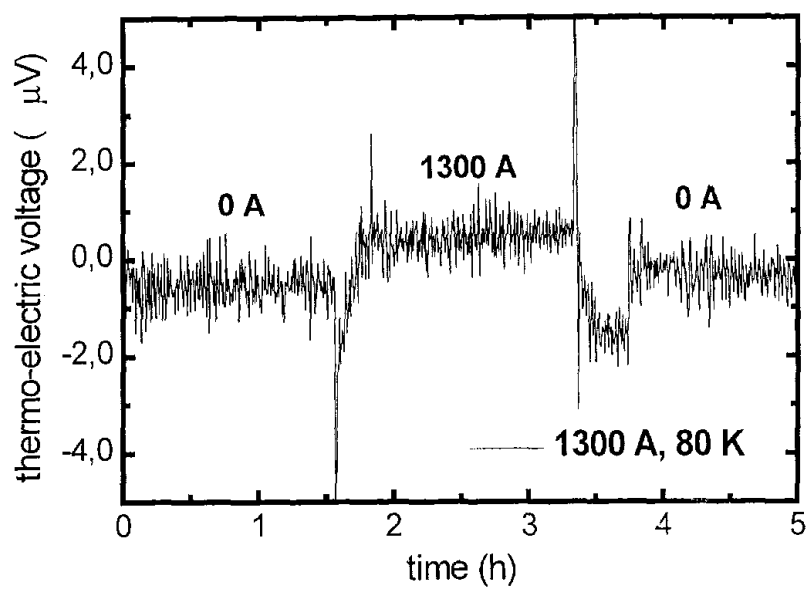

Fig. 2. Voltage signal from the thermocouples located inside the cable and separated by $7.0 \mathrm{~m}$. No-load $=0 \mathrm{~A}$ and load $=1300 \mathrm{~A}$.

\section{RESULTS}

Fig. 2 shows a thermocouple measurement spanning five hours. During this time, the conductor carried $1300 \mathrm{~A}$ rms $(50 \mathrm{~Hz})$ for almost two hours. In addition, data are recorded before and after running the conductor with load, in order to determine the zero level (i.e., with no-load) accurately. The dip after the energized period is due to an accelerated cooling procedure where the flow rate is increased. For the rest of the curve, the flow rate is kept constant at $0.147 \mathrm{~kg} / \mathrm{s}$. In Fig. 2, the spread in data is almost $\pm 1 \mu \mathrm{V}$, and a slight drift in the zero level can be detected. Fig. 3 results from a zero compensation and a simple averaging procedure ( 21 points). In Fig. 3 , the spread in data is reduced to less than $\pm 0.5 \mu \mathrm{V}$, and the zero drift is eliminated. The thermocouple voltage for the energized period can be determined (in Fig. 3 "estimated") to $0.9 \mu \mathrm{V} \pm 0.6 \mu \mathrm{V}(95 \%$ confidence interval). From the instream diode, the temperature can be read as $80 \mathrm{~K}$. The thermoelectric sensitivity for an E-type thermocouple at $80 \mathrm{~K}$ is $26.8 \mu \mathrm{V} / \mathrm{K}$. Thus, thermopile made from two thermocouples provides a sensitivity of $53.6 \mu \mathrm{V} / \mathrm{K}$. With the use of the expression for mass flow, the heat dissipated into the LN2 can be obtained as

$$
P=c_{p}, \dot{m} \wedge T
$$

$P(\mathrm{~W})$ is the heat dissipated in the $\mathrm{LN} 2, c_{p}\left(\mathrm{Jkg}^{-1} \mathrm{~K}^{-1}\right)$ is the specific heat of LN2 at constant temperature, $m\left(\mathrm{kgs}^{-1}\right)$ is the flow rate and $\Delta T(\mathrm{~K})$ the temperature difference over the thermocouple. With $c_{p}=2.05\left(\mathrm{~kJ}^{\mathrm{kg}} \mathrm{kg}^{-1} \mathrm{~K}^{-1}\right)$ and by using the thermal sensitivity of the E-type thermocouple, a $\Delta T$ of 0.017 $\mathrm{K}$ can be calculated. This leads by (1) to a dissipated heat of $P=5.1 \mathrm{~W}$ in the $7 \mathrm{~m}$ long conductor, which is $0.73 \mathrm{~W} / \mathrm{m}$. The error of this number is related to with what precision the temperature difference $\Delta T$, and thereby how precise the change in thermoelectric voltage can be determined. The $95 \%$ confidence interval is about $\pm 0.6 \mu \mathrm{V}$, or in this case about $60 \%$. The error of the Coriolis flow meter reading is better than $1 \%$, i.e. negligible. The resulting error in the

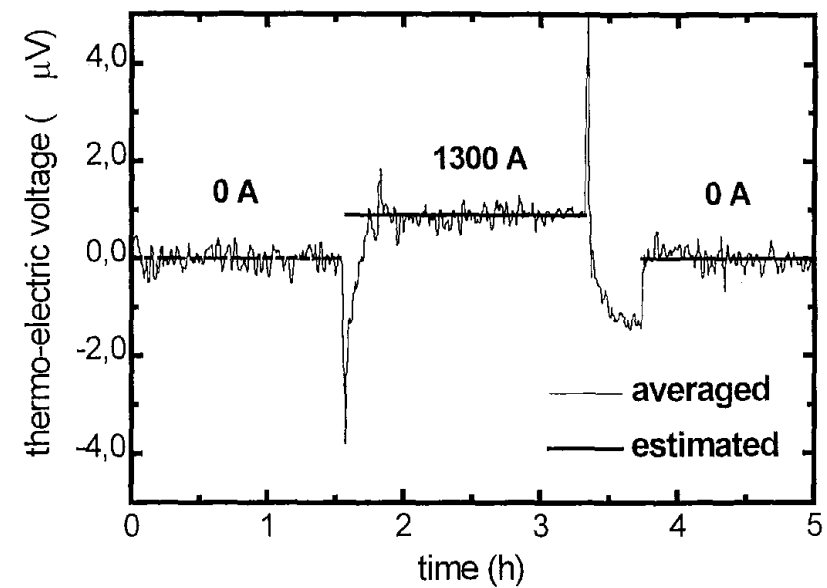

Fig. 3. Same as Fig. 2, but zero level compensated and data averaged. Voltage level for energized cable indicated by a straight line (estimated)

power dissipation $P$ is about $3.6 \mathrm{~W}$ or $0.6 \mathrm{~W} / \mathrm{m}$ for this experiment $(1300 \mathrm{~A}$ and $0.147 \mathrm{~kg} / \mathrm{s})$. By decreasing the flow rate, and by performing a better data reduction, the error can be decreased.

In Fig. 4, similar calorimetric data are plotted (open circles) for currents of 800 to $2000 \mathrm{~A}$ rms. With the same operating conditions, a total loss curve is obtained in the range 200 to $2000 \mathrm{~A}$ rms using phase sensitive electrical measurements with inductive compensation. This is plotted in Fig. 4 as the heavy line. The two data sets agree within the range of overlap ( 800 to $2000 \mathrm{~A}$ ). Therefore, it is plausible to assume that the two data sets represent the same loss curve for the superconductor in the SS cryostat. This is substantiated by comparison with earlier measurements performed in a metal free environment. In order to get the "pure" hysteretic loss of the conductor, it is necessary to subtract the eddy current loss originating in the SS cryostat due to magnetic field generated by current through the conductor. The eddy current loss follows an $\mathrm{I}^{2}$ law, where $\mathrm{I}$ is the rms current in the conductor. Thus, by accounting for the $\mathrm{I}^{2}$ contribution, the dashed curve in Fig. 4 is obtained. Thus, the total electrical losses are a factor of two larger than the hysteretic losses.

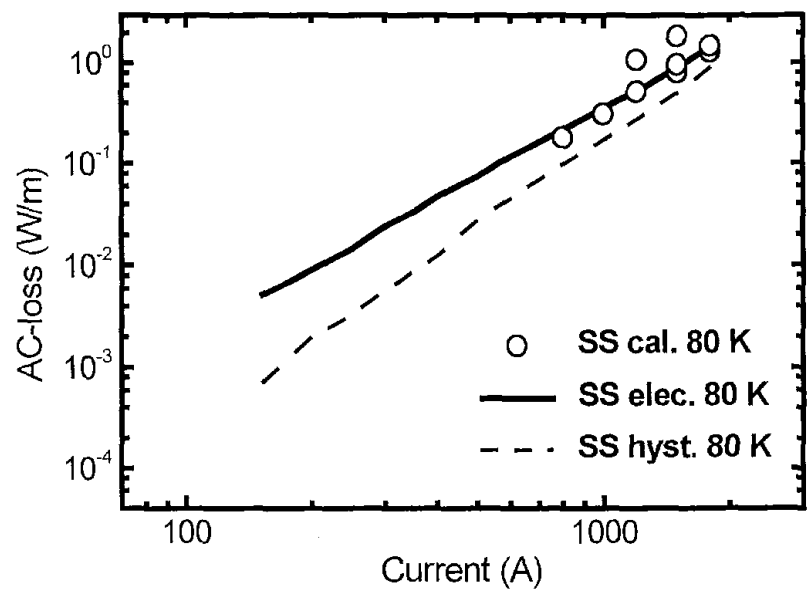

Fig. 4. Ac losses versus rms current. Open circles are calorimetric data. Full and dashed line are electrical data. 
The thermal loss (and pumping loss) is incorporated in the zero level. In no-load condition, only the thermal loss is present, which can be determined by logging the change in zero level versus flow rate. The no-load loss for this cryostat is determined as $3.7 \mathrm{~W} / \mathrm{m} \mathrm{[2]}$ and $2.6 \mathrm{~W} / \mathrm{m} \mathrm{[10],} \mathrm{which} \mathrm{agrees}$ with the heat leak of $2.5 \mathrm{~W} / \mathrm{m}$ given by the manufacturer of the cryostat.

Earlier measurements [1] of the ac loss performed at $77 \mathrm{~K}$ on the conductor in a metal free environment tend to be lower than the values obtained in the SS cryostat. However, two major differences have to be considered. The loss measured in the SS cryostat is the total electrical loss generated by current through the conductor whereas the data obtained in the metal free environment involve only the hysteretic loss of the superconductor. Further, there is a temperature difference of about $3 \mathrm{~K}$ between data taken in the SS cryostat and in the metal free environment. It seems reasonable to explain this discrepancy with the $3 \mathrm{~K}$ temperature difference. Further, a slightly larger joint resistance at the superconductor end and a temperature gradient of the order of $1 \mathrm{~K}$ in the SS cryostat experiment would cause a change in the current distribution of the superconductor. Qualitatively these factors combine to increase the expected loss when the conductor is placed in the SS cryostat. In this sense, the two sets of data, although different, must be regarded as representing a coherent picture of the $10 \mathrm{~m}$ long model superconductor.

\section{CONCLUSLON}

With a simple calorimetric measurement, we have determined the ac losses of a $10 \mathrm{~m}$ long superconducting cable model. The electrical and the calorimetric measurements were in good agreement. The test system is suitable for determining the load and no-load dissipation of other electrical power components as well as for a three phase cable arrangement. The thermal resolution of the experiment is dependent on each component. For the $10 \mathrm{~m}$ long conductor, we obtained a resolution in the range $0.6 \mathrm{~W} / \mathrm{m}$. For cables in general, the resolution should increase with the length because the temperature difference between the ends of the cable increases with length.

\section{ACKNOWLEDGMENT}

NKT Research is acknowledged for their outstanding collaboration, for providing the cable conductor and for fruitful discussions.

\section{REFERENCES}

[1] S. Krïger Olsen, A. v. Aa Kühle, C. Traholt, C. Rasmussen, O. Tonnesen, M. Däumling, C. N. Rasmussen, D. W. A. Willén, "Alternating current losses of a 10 meter long low loss superconducting cable conductor," Supercond. Sci. Technol., vol, 12, pp. 360-365, 1999.

[2] C. Traholt, C. Rasmussen, A. v. Aa Kühle, S. Krüger Olsen, K. Høj Jensen, O. Tøunesen, D. W. A. Willén, M. Dăumling, C. N. Rasmussen, "Operating a cryogenic test tig for a 10 meter long liquid nitrogen cooled superconducting power cable," Adv. Cryogenic Engineering, vol. 45 B, pp. 1517-1524, 1999.

[3] E. Cereda, G. Coletta, G. Crotti, L.Gherardi, G. Ottoboni, S. Zannella, "Comparison between self-field AC losses of single-phase Bi2223 cable measured by electrical and calorimetric methods", Physica $C$, vol. 310 , pp 231-235, 1998.

[4] G. Coletta, L.Gherardi, F. Gömöry, E. Cereda, G. Ottoboni, D Daney, M. Maley, S. Zannella, "Application of electrical and calorimetric methods to the ac loss characterization of cable conductors". IEEE Trans. Appl. Supercond., vol. 9 (2), pp 1053-1056, 1999.

[5] M. Leghissa, J. Rieger, J. Wiezoreck, H.-W. Neumüiller, "HTS cables for electric power transmission - Basic properties - State of the art Prospects", Adv. Solid State Phys. Vol. 38, 1998.

[6] DeMaCo Holland BV, NL-1700 BB Heerhugowaard, Netherlands.

[7] Messer Cryotherm CimbH \& Co. KG, D-57555 Euteneuen, Germany

[8] C. N. Rasmussen, C. Rasmussen, "Optimization of termination for high temperature superconducting cable with a room temperature dielectric design," IEEE Trans. Appl. Supercond, vol. 9, pp. 45-48, 1999.

[9] C. Rasmussen, A. v. Aa Kühle, O. Tømmesen, C. N. Rasmussen, "Design of a termination for high temperature superconducting power cable." IEEE Trans. Appl. Supercond, vol. 9, pp. 1273-1276, 1999.

[10] E. Veje, C. Traholt, O. Tøunesen, "Determination of the heat transfer between a $10 \mathrm{~m}$ long cryostat and its surroundings," submitted for publication in these proceedings. 